Supporting Information

\title{
Acetal-Functionalized Pillar[5]arene: a pH-Responsive and Versatile Nanomaterial for the Delivery of Chemotherapeutic Agents
}

\author{
Shang Lan, Yamin Liu, Kejia Shi and Da Ma*
}

Department of Chemistry, Fudan University, 220 Handan Road, Shanghai 200433, China

*Email: dama@fudan.edu.cn

\section{Table of Contents}

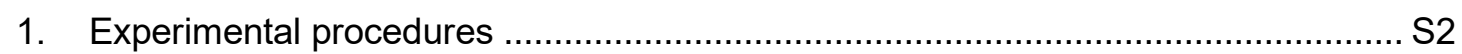

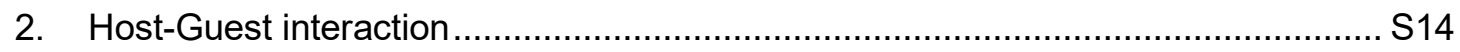

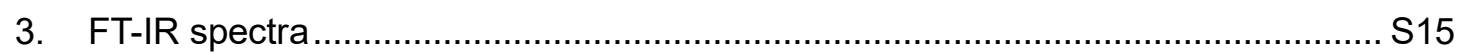

4. Morphology and size distributions of nanoparticles............................. 16

5. Time-dependent size change of nanoparticles................................. 17

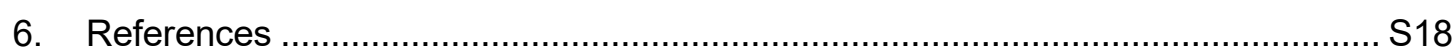




\section{Experimental procedures}

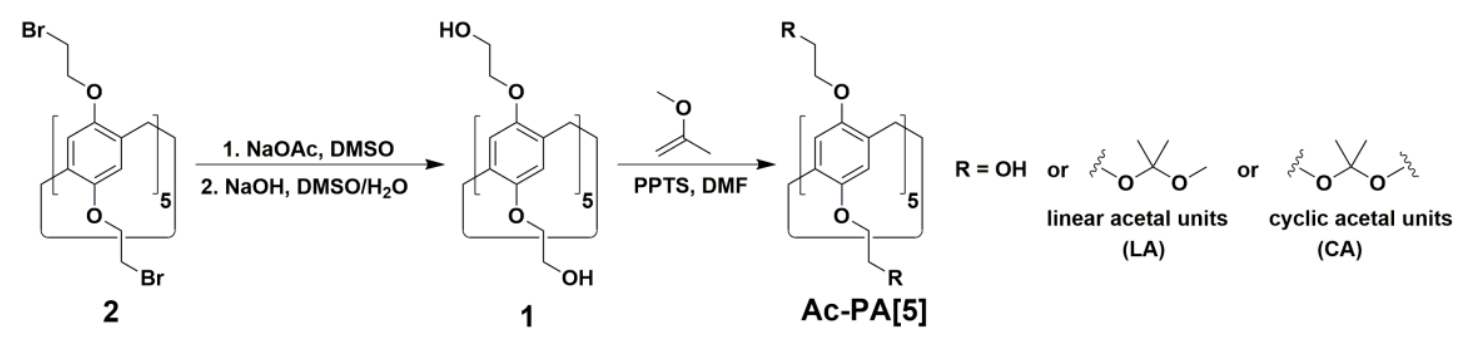

\subsection{Synthesis of Ac-PA[5].}

Synthesis of host 1: Host 2 was first synthesized according to reported literature procedures. ${ }^{1}$ $\mathrm{NaOAc}(1.23 \mathrm{~g}, 15 \mathrm{mmol})$ was added into a solution of host $2(1.68 \mathrm{~g}, 1 \mathrm{mmol})$ in DMSO $(50 \mathrm{~mL})$. The mixture was stirred at $90{ }^{\circ} \mathrm{C}$ for $3 \mathrm{~h}$. Aqueous $\mathrm{NaOH}(15 \mathrm{~mL}, 15 \mathrm{mmol})$ was added to the reaction mixture and stirred for $30 \mathrm{~min}$. The reaction mixture was poured into $\mathrm{H}_{2} \mathrm{O}$, the product was collected by centrifugation at $10000 \mathrm{rpm}$, then rinsed with $\mathrm{H}_{2} \mathrm{O}(3 \times 30 \mathrm{~mL})$. The product was recrystallized from methanol to obtain host 1 as a white solid (540 mg, 51\%). ${ }^{1} \mathrm{H}$ NMR (400 MHz, MeOD) $\delta(\mathrm{ppm}): 6.95(\mathrm{~s}, 10 \mathrm{H}), 3.95(\mathrm{t}, J=4.7 \mathrm{~Hz}, 20 \mathrm{H}), 3.88(\mathrm{t}, J=4.8 \mathrm{~Hz}, 20 \mathrm{H}), 3.82(\mathrm{~s}$, 10H). ${ }^{13} \mathrm{C}$ NMR (100 MHz, MeOD) $\delta(\mathrm{ppm}): 151.16,130.33,116.05,71.35,62.19,30.17$.
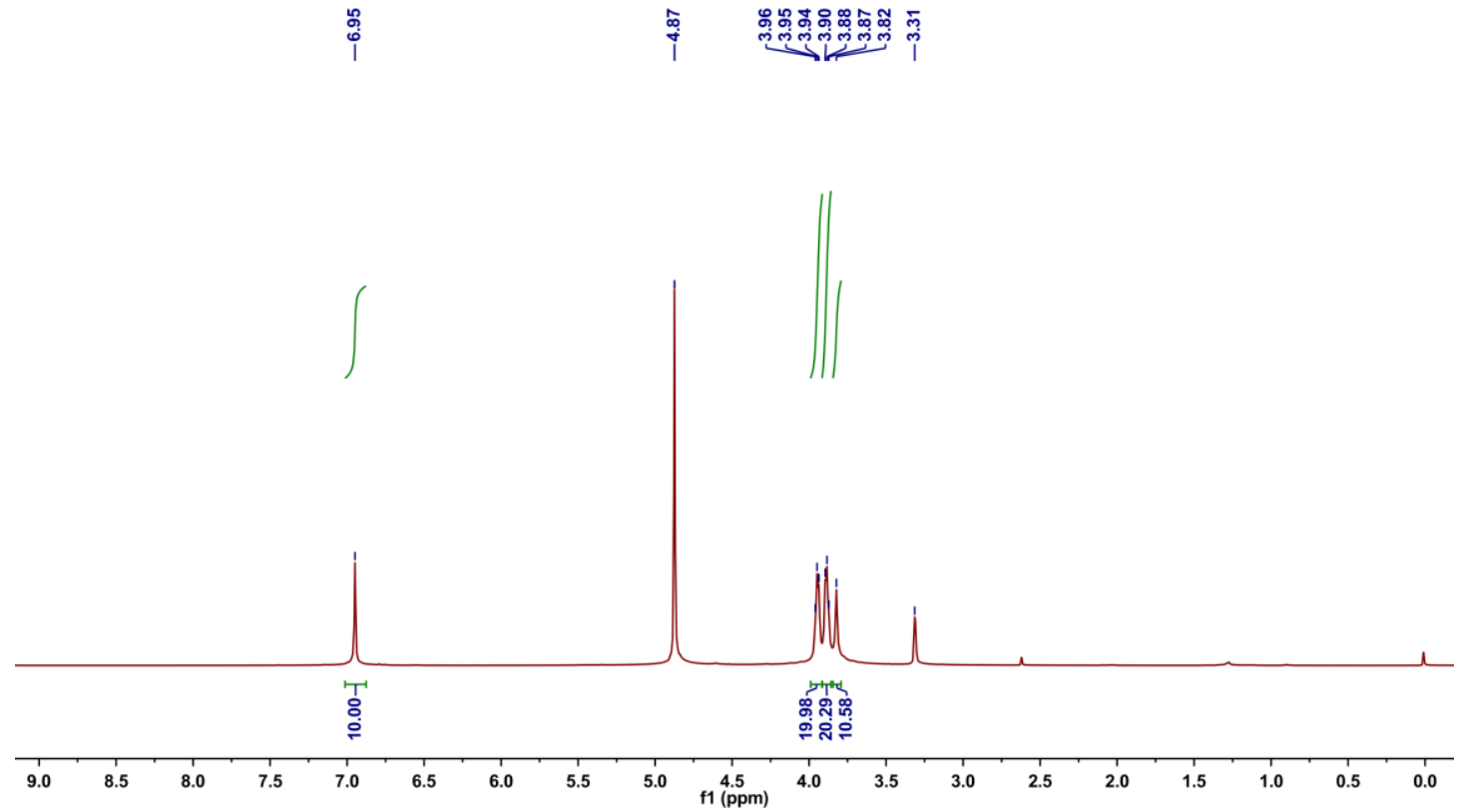

Figure S1. ${ }^{1} \mathrm{H}$ NMR spectrum (400 MHz, MeOD) of host 1. 


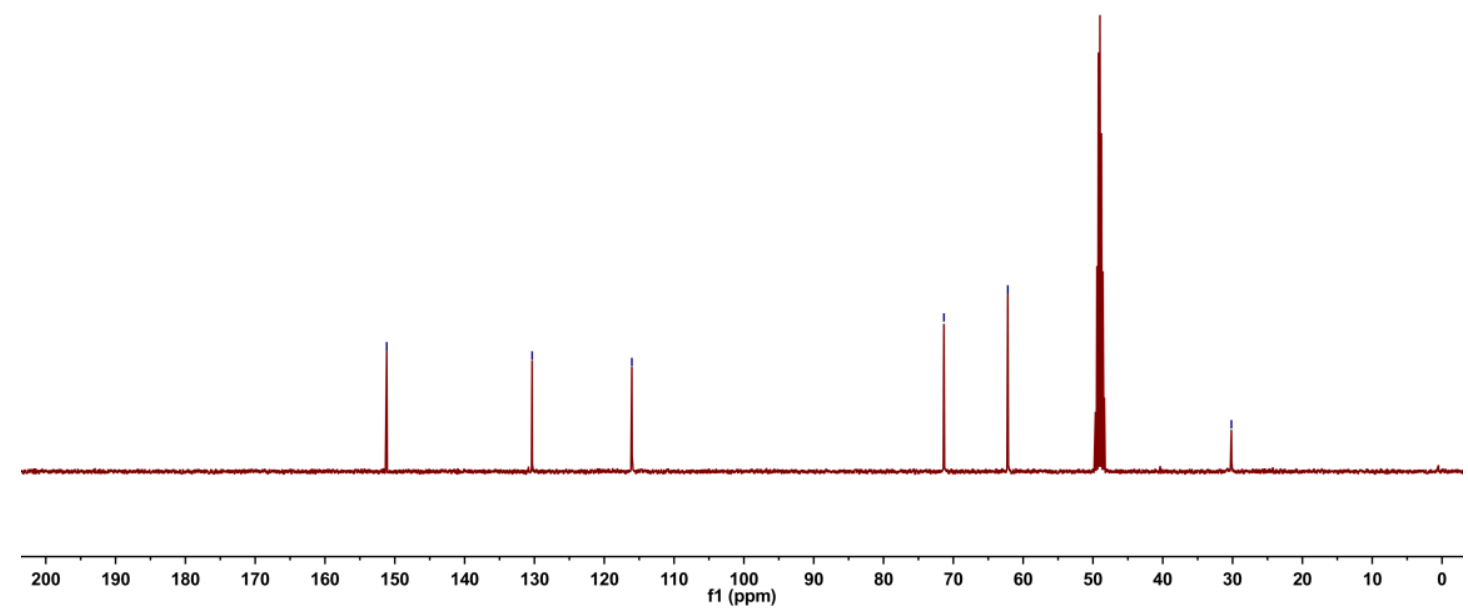

Figure S2. ${ }^{13} \mathrm{C}$ NMR spectrum (100 MHz, MeOD) of host 1.

Synthesis of $\boldsymbol{A c - P A}[\mathbf{5}]^{2}$ : A flame-dried flask was charged with host 1 (1.05 g, $\left.1 \mathrm{mmol}\right)$ and purged with $\mathrm{N}_{2}$. Anhydrous DMF (50 mL) was added and the resulting mixture was stirred until host 1 was completely dissolved. Pyridium $p$-toluenesulfonate $(25 \mathrm{mg}, 0.1 \mathrm{mmol})$ was added followed by 2-methoxypropene $(1.9 \mathrm{~mL}, 20 \mathrm{mmol})$. The system was maintained under positive $\mathrm{N}_{2}$ pressure and then sealed. After $3 \mathrm{~h}$, the reaction was quenched with trimethylamine $(0.5 \mathrm{~mL})$. The product was precipitated with $\mathrm{H}_{2} \mathrm{O}$ and isolated by centrifugation. The resulting product was washed thoroughly with $\mathrm{H}_{2} \mathrm{O}$ and lyophilized to obtain Ac-PA[5] as a white powder $(0.73 \mathrm{~g})$. 


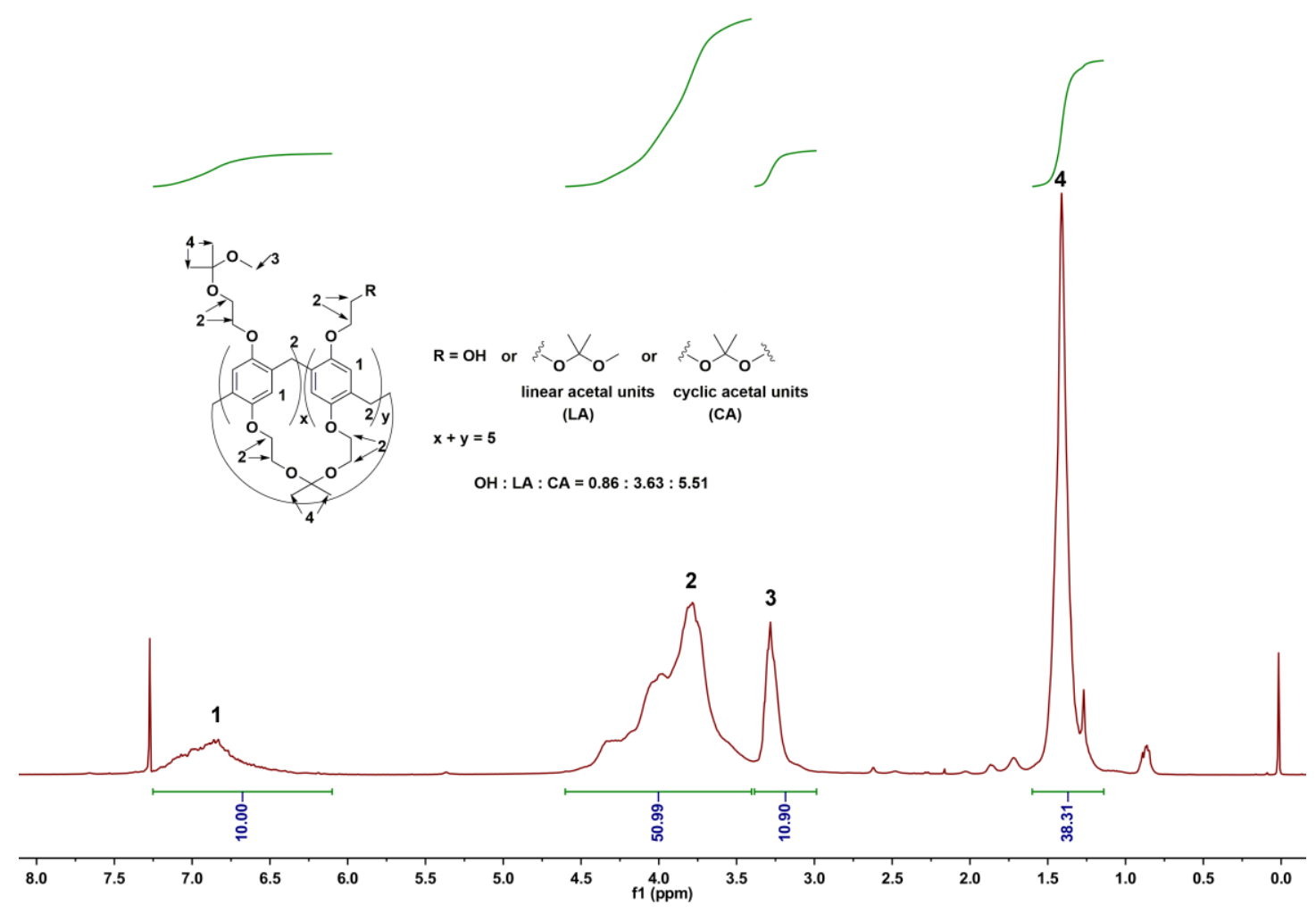

Figure S3. ${ }^{1} \mathrm{H}$ NMR spectrum ( $400 \mathrm{MHz}, \mathrm{CDCl}_{3}$ ) recorded for Ac-PA[5].

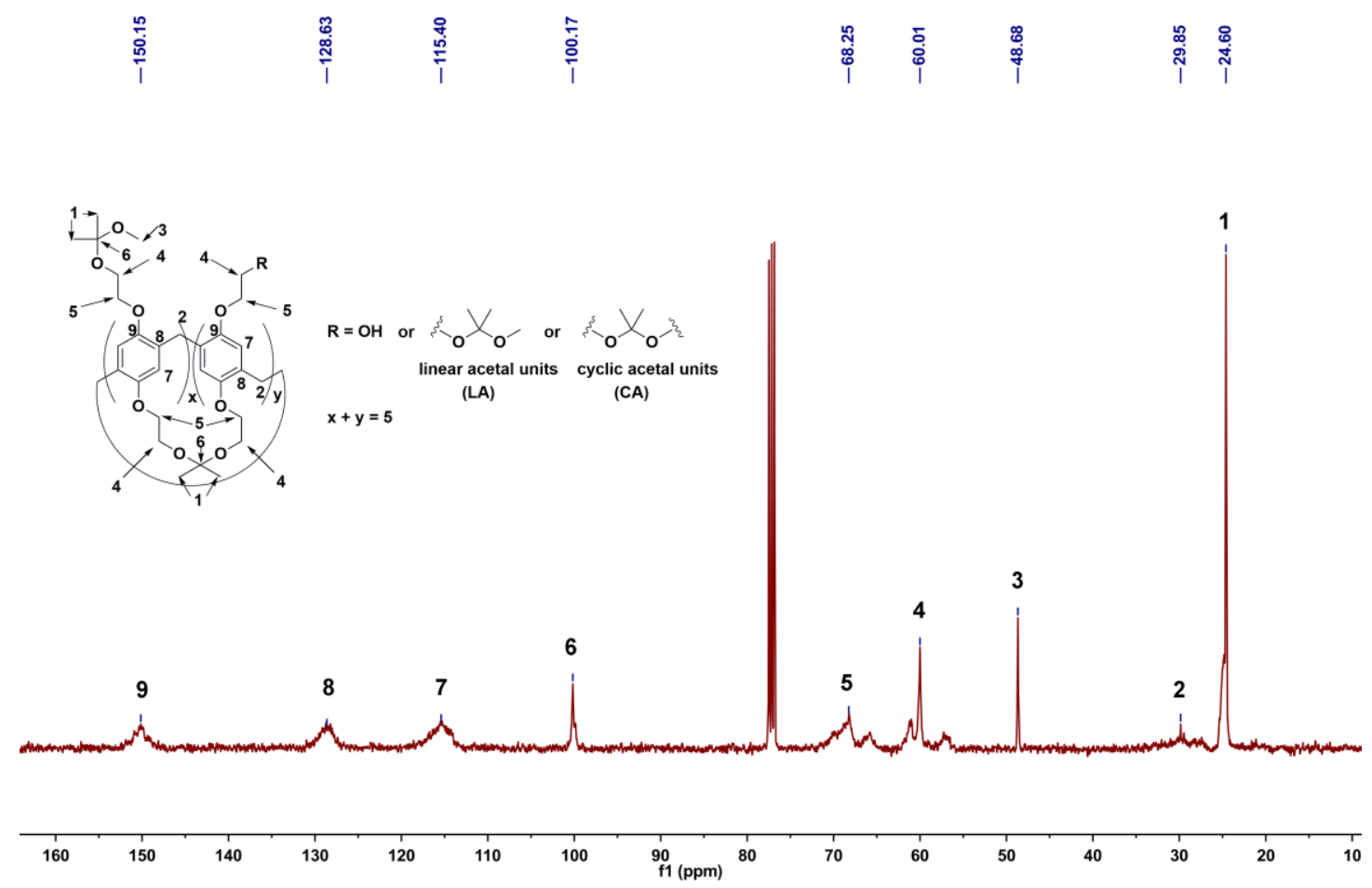

Figure S4. ${ }^{13} \mathrm{C}$ NMR spectrum $\left(100 \mathrm{MHz}, \mathrm{CDCl}_{3}\right)$ recorded for Ac-PA[5]. 

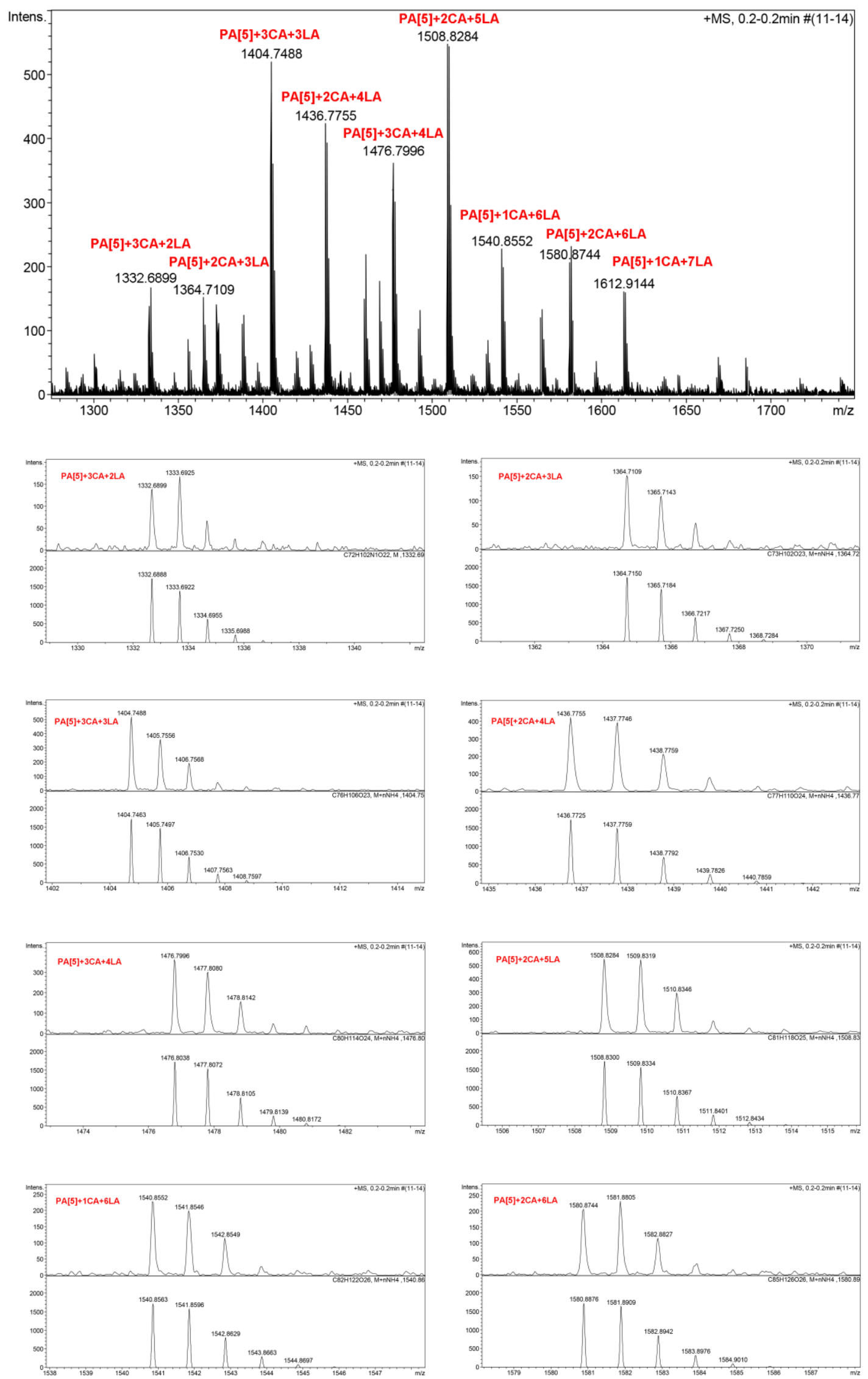


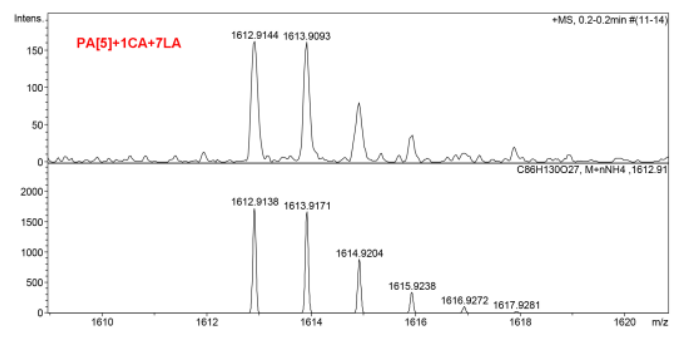

Figure S5. Electrospray ionization mass spectra of Ac-PA[5].

Note: In the mass spectra of Ac-PA[5], LA = linear acetal units, CA = cyclic acetal units, $\mathrm{PA}[5]+m \mathrm{CA}+n \mathrm{LA}$ represents the number of CA and LA unit in acetalated PA[5] molecule is $m$ and $n$, respectively.

\begin{tabular}{|c|c|c|c|}
\hline molecules & Experimental[M+N $\left[\mathrm{NH}_{4}\right]^{+}$ & Calculated $\left[\mathrm{M}+\mathrm{NH}_{4}\right]^{+}$ & Error (ppm) \\
\hline $\mathrm{PA}[5]+1 \mathrm{CA}+6 \mathrm{LA}$ & 1540.8552 & 1540.8563 & 0.7 \\
\hline $\mathrm{PA}[5]+1 \mathrm{CA}+7 \mathrm{LA}$ & 1612.9144 & 1612.9138 & 0.4 \\
\hline $\mathrm{PA}[5]+2 \mathrm{CA}+3 \mathrm{LA}$ & 1364.7109 & 1364.7150 & 3.0 \\
\hline $\mathrm{PA}[5]+2 \mathrm{CA}+4 \mathrm{LA}$ & 1436.7755 & 1436.7725 & 2.1 \\
\hline $\mathrm{PA}[5]+2 \mathrm{CA}+5 \mathrm{LA}$ & 1508.8284 & 1508.8300 & 1.1 \\
\hline $\mathrm{PA}[5]+2 \mathrm{CA}+6 \mathrm{LA}$ & 1580.8744 & 1580.8876 & 8.3 \\
\hline $\mathrm{PA}[5]+3 \mathrm{CA}+2 \mathrm{LA}$ & 1332.6899 & 1332.6888 & 0.8 \\
\hline $\mathrm{PA}[5]+3 \mathrm{CA}+3 \mathrm{LA}$ & 1404.7488 & 1404.7463 & 1.8 \\
\hline $\mathrm{PA}[5]+3 \mathrm{CA}+4 \mathrm{LA}$ & 1476.7996 & 1476.8038 & 2.8 \\
\hline
\end{tabular}

Table S1 Experimental and calculated E/Z values found for Ac-PA[5] and corresponding error (ppm)

\subsection{Synthesis of FITC-Py and FA-Py.}

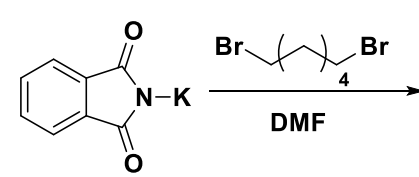<smiles>CC(C)(Br)CCN1C(=O)c2ccccc2C1=O</smiles><smiles>Cc1ccccc1</smiles><smiles>CC(C)(CCN1C(=O)c2ccccc2C1=O)n1cccc1</smiles>

3 4

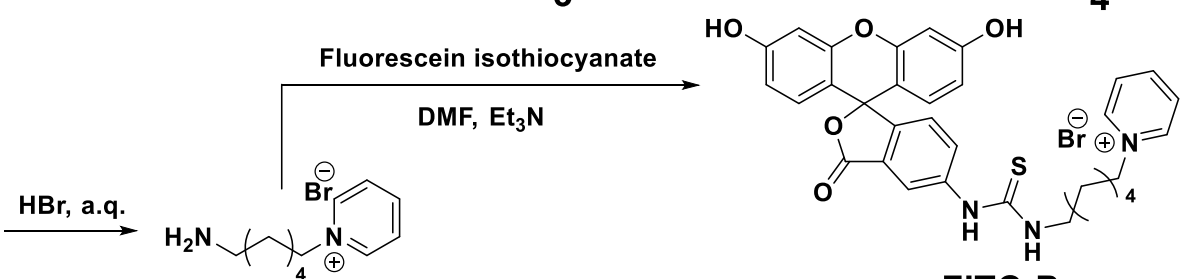

5

FITC-Py

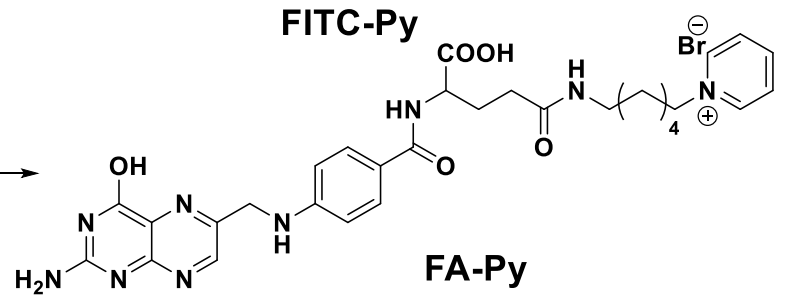


Synthesis of compound $3^{3}$ : A solution of 1,6-dibromohexane (12.25 g, $\left.50 \mathrm{mmol}\right)$ and potassium phthalimide $(1.86 \mathrm{~g}, 10 \mathrm{mmol})$ in DMF $(10 \mathrm{~mL})$ was stirred at $90{ }^{\circ} \mathrm{C}$ for $24 \mathrm{~h}$. After the mixture was cooled to room temperature, the solvent was removed by reduced pressure. The crude mixture was purified by column chromatography on silica gel to giva a white solid (2.76 g, 89\%). ${ }^{1} \mathrm{H}$ NMR (400 MHz, $\left.\mathrm{CDCl}_{3}\right) \delta(\mathrm{ppm}): 7.84(\mathrm{dd}, J=5.4,3.1 \mathrm{~Hz}, 2 \mathrm{H}), 7.71(\mathrm{dd}, J=5.5,3.0 \mathrm{~Hz}, 2 \mathrm{H})$, $3.68(\mathrm{t}, J=7.2 \mathrm{~Hz}, 2 \mathrm{H}), 3.39(\mathrm{t}, J=6.8 \mathrm{~Hz}, 2 \mathrm{H}), 1.89-1.82(\mathrm{~m}, 2 \mathrm{H}), 1.73-1.66(\mathrm{~m}, 2 \mathrm{H}), 1.52-$ $1.45(\mathrm{~m}, 2 \mathrm{H}), 1.41-1.33(\mathrm{~m}, 2 \mathrm{H}) .{ }^{13} \mathrm{C} \mathrm{NMR}\left(100 \mathrm{MHz}, \mathrm{CDCl}_{3}\right) \delta(\mathrm{ppm}): 168.58,134.03,132.29$, $123.33,37.98,33.79,32.74,28.54,27.84,26.16$.

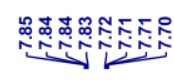

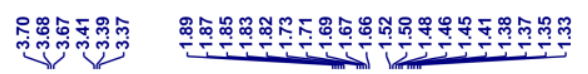
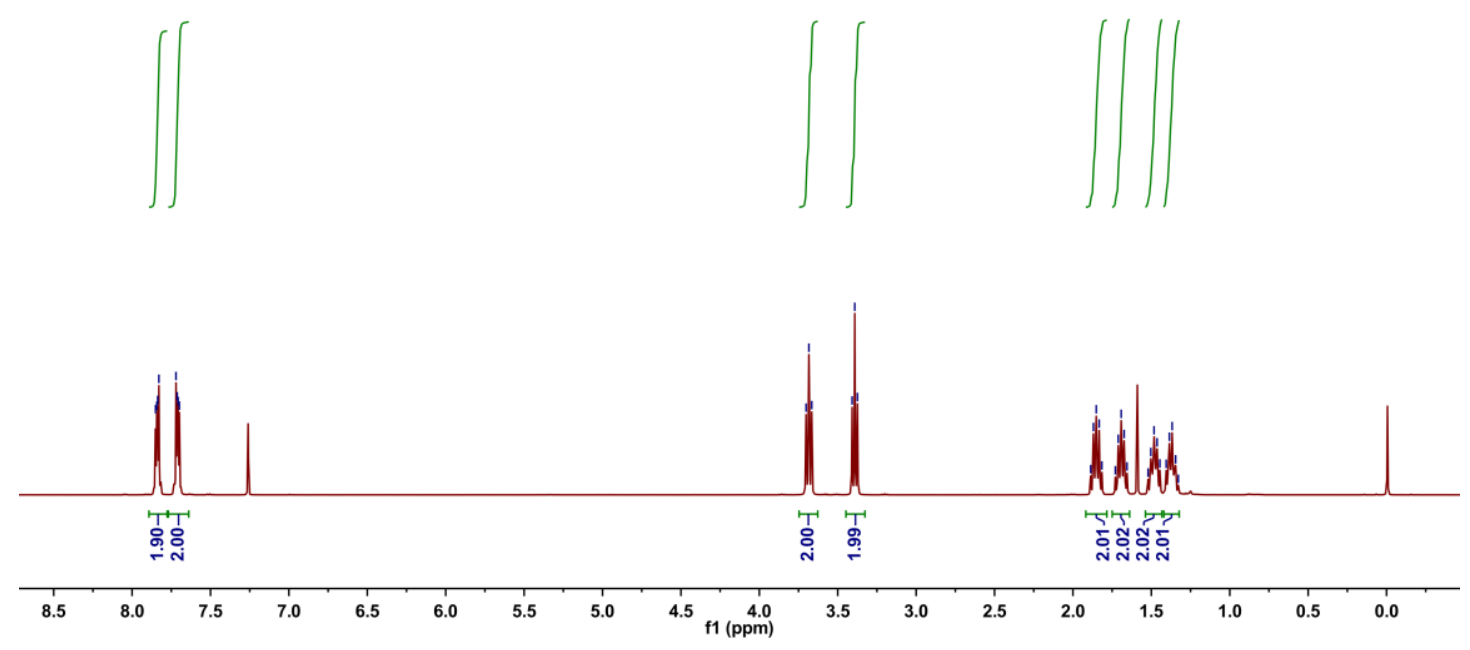

Figure S6. ${ }^{1} \mathrm{H}$ NMR spectrum $\left(400 \mathrm{MHz}, \mathrm{CDCl}_{3}\right)$ recorded for compound 3.
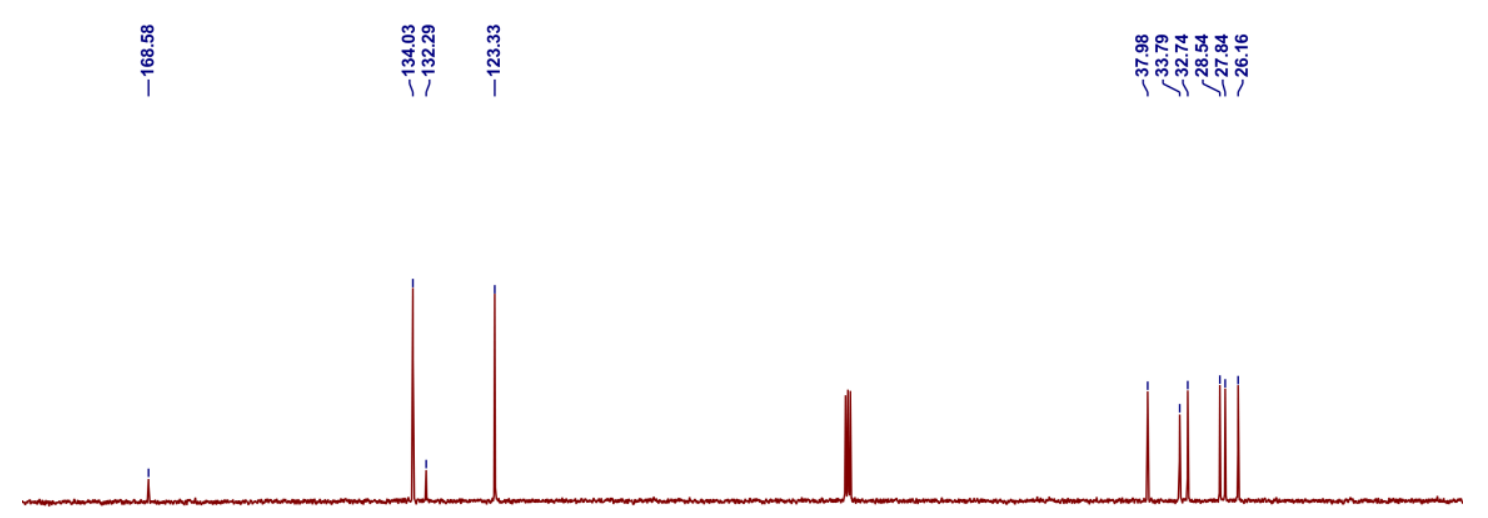

$\begin{array}{lllllllllllllllll}180 & 170 & 160 & 150 & 140 & 130 & 120 & 110 & 100 & 90 & 90 & 1 & 1 & 1 & 1 & 1 & 1 \\ \mathrm{fpm}) & 80 & 70 & 60 & 50 & 40 & 30 & 20 & 10 & 0\end{array}$

Figure S7. ${ }^{13} \mathrm{C}$ NMR spectrum $\left(100 \mathrm{MHz}, \mathrm{CDCl}_{3}\right)$ recorded for compound 3 . 
Synthesis of compound $4^{3}$ : Compound $3(3.11 \mathrm{~g}, 10 \mathrm{mmol})$ was dissolved in dry pyridine (10 $\mathrm{mL}$ ), and the resulting solution was heated to reflux for $3 \mathrm{~h}$. After cooling to room temperature, the mixture was poured into diethyl ether $(30 \mathrm{~mL})$. The product was collected by centrifugation and washed with diethyl ether $(3 \times 30 \mathrm{~mL})$ to give a white solid $(3.7 \mathrm{~g}, 95 \%) .{ }^{1} \mathrm{H}$ NMR $\left(400 \mathrm{MHz}, \mathrm{D}_{2} \mathrm{O}\right)$ $\delta(\mathrm{ppm}): 8.87(\mathrm{~d}, J=6.0 \mathrm{~Hz}, 2 \mathrm{H}), 8.55(\mathrm{t}, J=7.9 \mathrm{~Hz}, 1 \mathrm{H}), 8.08(\mathrm{t}, J=7.0 \mathrm{~Hz}, 2 \mathrm{H}), 7.74(\mathrm{dd}, J=$ 5.6, $3.1 \mathrm{~Hz}, 2 \mathrm{H}), 7.67(\mathrm{dd}, J=5.8,2.9 \mathrm{~Hz}, 2 \mathrm{H}), 4.63(\mathrm{t}, J=7.3 \mathrm{~Hz}, 2 \mathrm{H}), 3.52(\mathrm{t}, J=7.0 \mathrm{~Hz}, 2 \mathrm{H})$, $2.06-1.98(\mathrm{~m}, 2 \mathrm{H}), 1.61-1.54(\mathrm{~m}, 2 \mathrm{H}), 1.41-1.28(\mathrm{~m}, 4 \mathrm{H}) .{ }^{13} \mathrm{C} \mathrm{NMR}\left(100 \mathrm{MHz}, \mathrm{D}_{2} \mathrm{O}\right) \delta(\mathrm{ppm})$ : $170.39,145.38,144.01,134.55,130.92,128.04,123.05,61.68,37.41,30.19,27.18,25.28,24.61$.
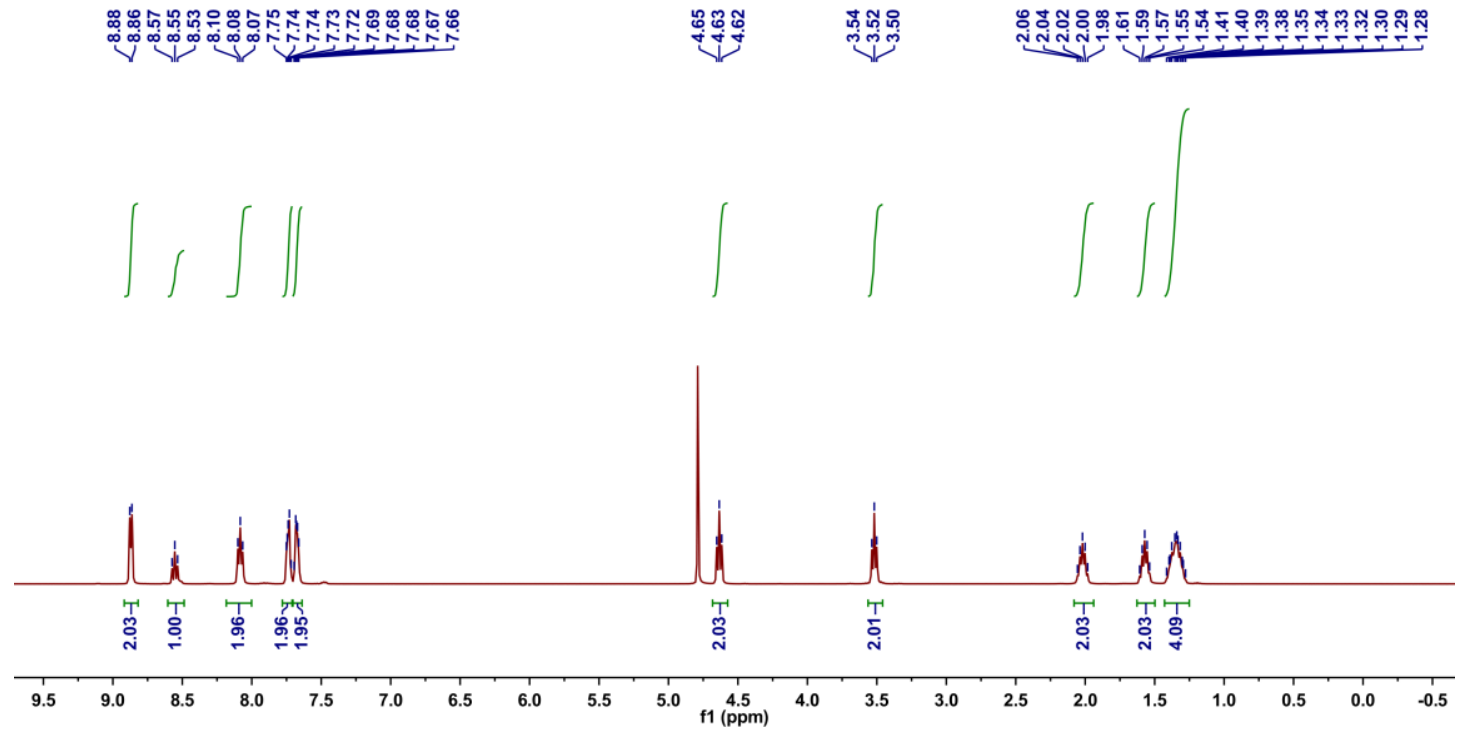

Figure S8. ${ }^{1} \mathrm{H}$ NMR spectrum $\left(400 \mathrm{MHz}, \mathrm{D}_{2} \mathrm{O}\right)$ recorded for compound 4.
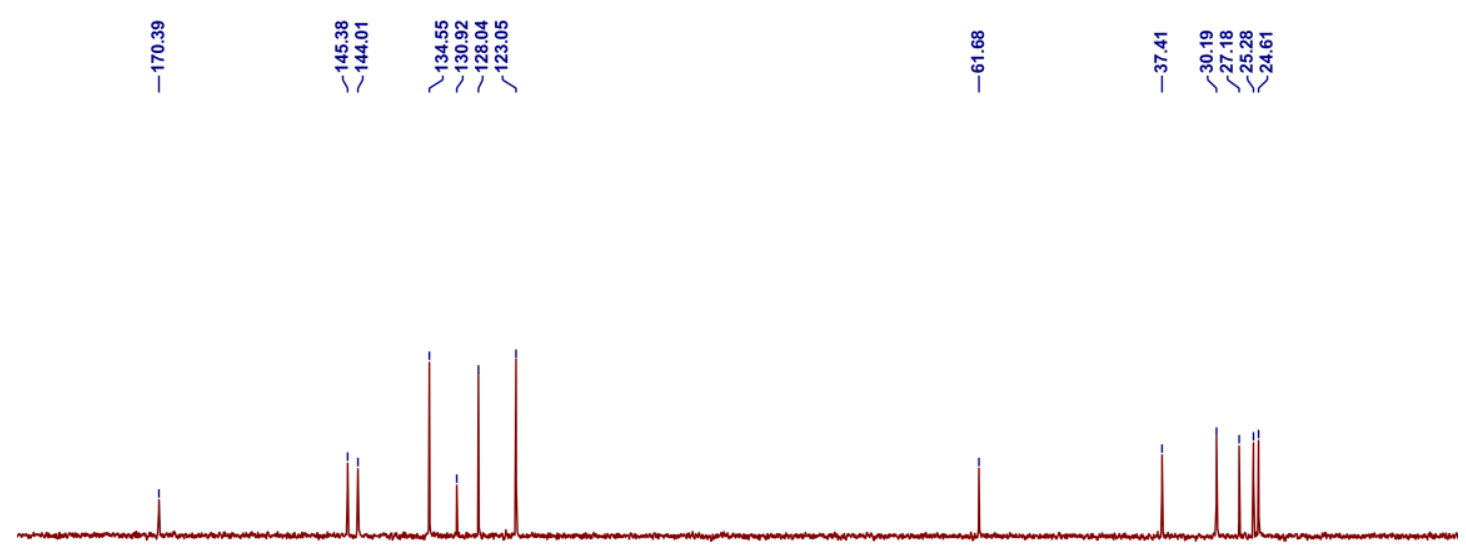

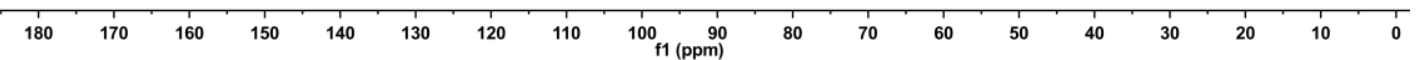

Figure S9. ${ }^{13} \mathrm{C}$ NMR spectrum $\left(100 \mathrm{MHz}, \mathrm{D}_{2} \mathrm{O}\right)$ recorded for compound 4 . 
Synthesis of compound $5^{3}$ : Compound 4 (3.89 g, $\left.10 \mathrm{mmol}\right)$ was dissolved in $40 \% \mathrm{HBr}$ solution $(30 \mathrm{~mL})$ and heated at reflux for $3 \mathrm{~h}$. The mixture was cooled in an ice bath, and the precipitate was removed by filtration. The aqueous filtrate was poured into acetone $(30 \mathrm{~mL})$. The product was collected by centrifugation and washed with acetone $(3 \times 30 \mathrm{~mL})$ to give a white solid $(2.9 \mathrm{~g}, 85 \%)$. ${ }^{1} \mathrm{H}$ NMR (400 MHz, $\left.\mathrm{D}_{2} \mathrm{O}\right) \delta(\mathrm{ppm}): 8.83(\mathrm{~d}, J=6.0 \mathrm{~Hz}, 2 \mathrm{H}), 8.53(\mathrm{t}, J=7.8 \mathrm{~Hz}, 1 \mathrm{H}), 8.05(\mathrm{t}, J=$ $7.0 \mathrm{~Hz}, 2 \mathrm{H}), 4.59(\mathrm{~d}, J=7.4 \mathrm{~Hz}, 2 \mathrm{H}), 2.96(\mathrm{t}, J=7.6 \mathrm{~Hz}, 2 \mathrm{H}), 2.06-1.99(\mathrm{~m}, 2 \mathrm{H}), 1.67-1.60(\mathrm{~m}$, 2H), 1.45 - 1.35 (m, 4H). ${ }^{13} \mathrm{C}$ NMR (100 MHz, $\left.\mathrm{D}_{2} \mathrm{O}\right) \delta(\mathrm{ppm}): 145.30,143.91,127.98,61.49,39.10$, $29.99,26.14,24.74,24.47$.

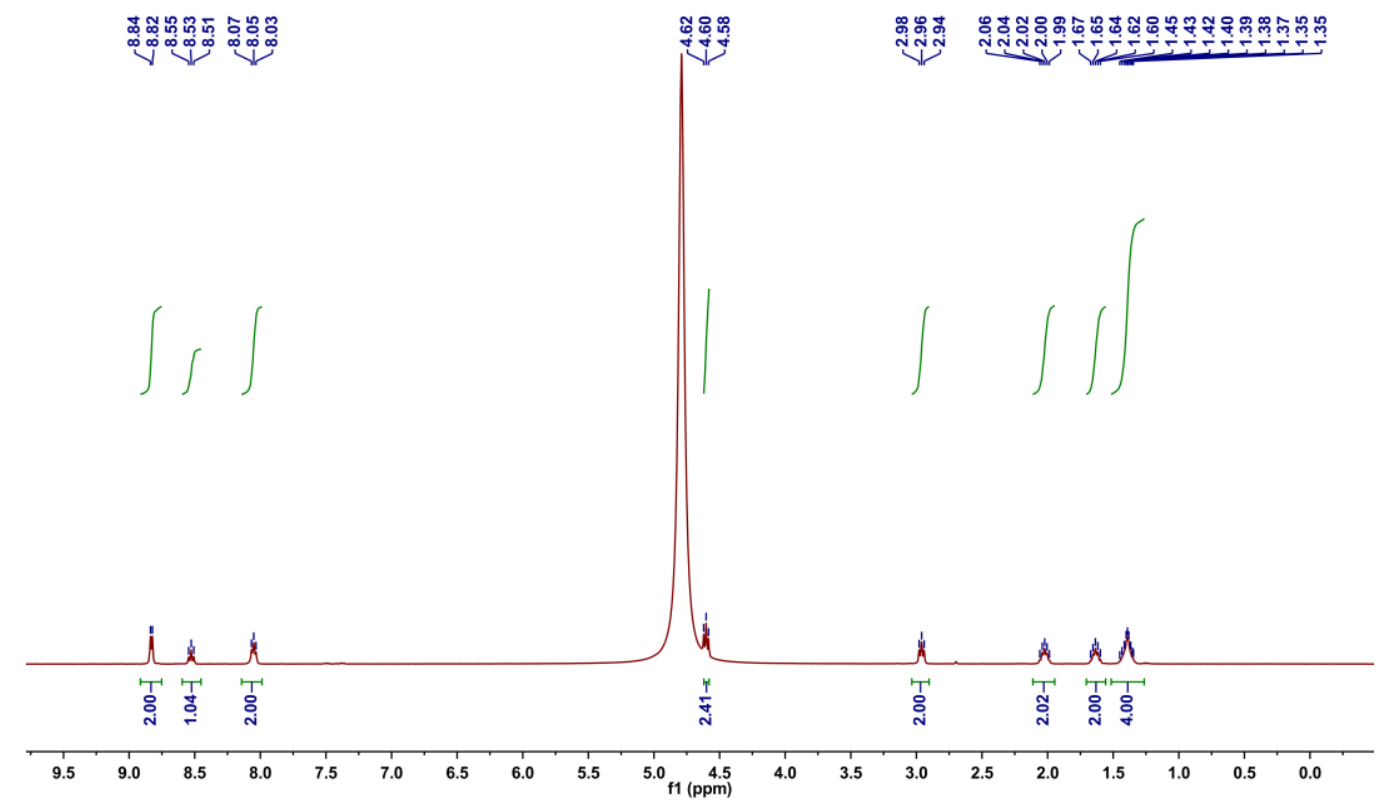

Figure S10. ${ }^{1} \mathrm{H}$ NMR spectrum $\left(400 \mathrm{MHz}, \mathrm{D}_{2} \mathrm{O}\right)$ recorded for compound 5.
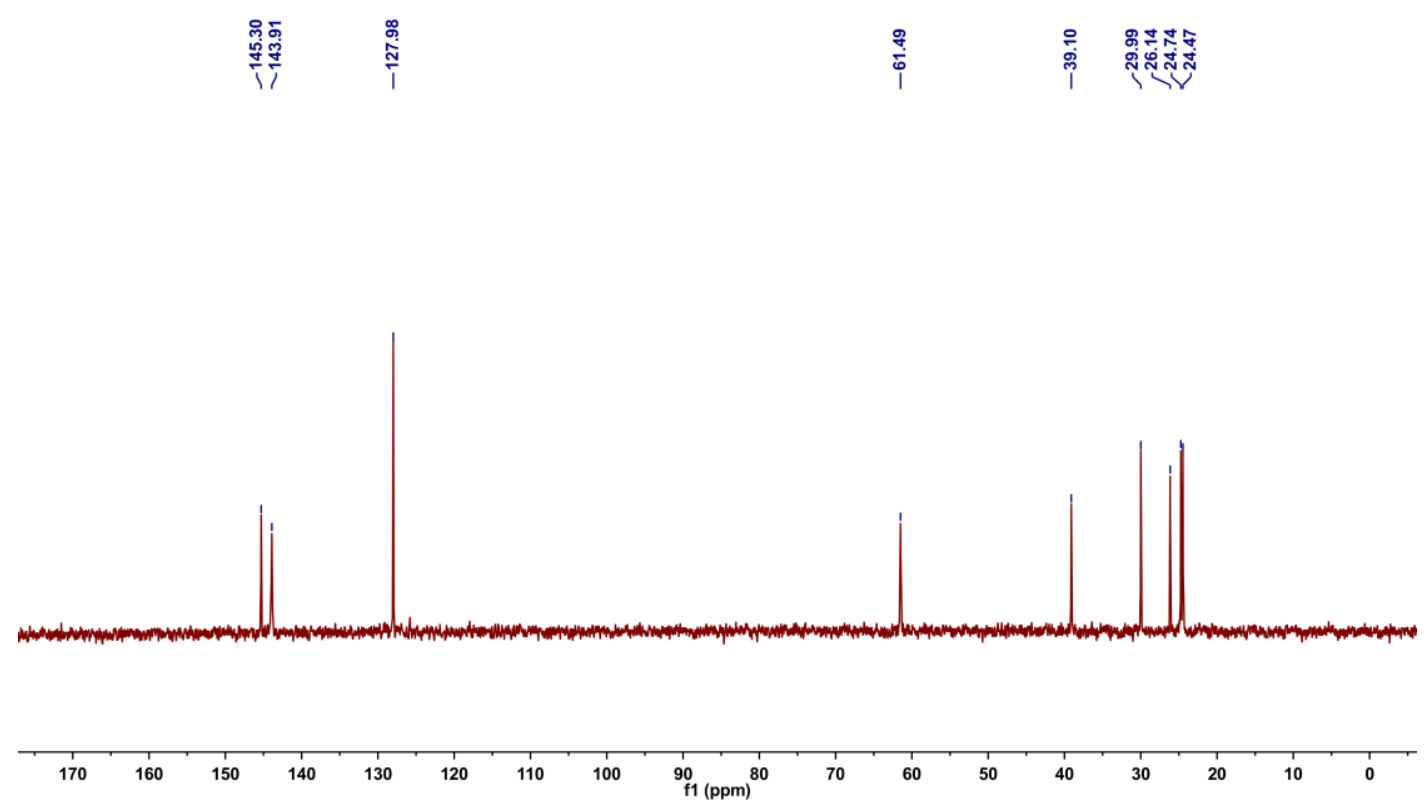

Figure S11. ${ }^{13} \mathrm{C}$ NMR spectrum $\left(100 \mathrm{MHz}, \mathrm{D}_{2} \mathrm{O}\right)$ recorded for compound 5. 
Synthesis of FITC-Py ${ }^{4}$ : Fluorescein isothiocyanate (389 mg, $1 \mathrm{mmol}$ ) and compound 5 (340 $\mathrm{mg}, 1 \mathrm{mmol})$ were dissolved in anhydrous DMF $(25 \mathrm{~mL})$. Et $\mathrm{t}_{3} \mathrm{~N}(200 \mu \mathrm{L})$ was added and the mixture was stirred for $3 \mathrm{~h}$ at room temperature in the dark. Then, the mixture was poured into diethyl ether $(100 \mathrm{~mL})$ and the orange precipitate was collected by centrifugation and washed with diethyl ether $(3 \times 30 \mathrm{~mL})$ to give an orange solid (508 mg, $80 \%) .{ }^{1} \mathrm{H}$ NMR (400 MHz, MeOD) $\delta(\mathrm{ppm}): 9.03(\mathrm{~d}$, $J=6.1 \mathrm{~Hz}, 2 \mathrm{H}), 8.59(\mathrm{t}, J=7.8 \mathrm{~Hz}, 1 \mathrm{H}), 8.21-8.04(\mathrm{~m}, 3 \mathrm{H}), 7.69$ (d, $J=8.2 \mathrm{~Hz}, 1 \mathrm{H}), 7.17(\mathrm{~d}, J=$ $8.3 \mathrm{~Hz}, 1 \mathrm{H}), 6.78(\mathrm{~d}, J=8.8 \mathrm{~Hz}, 2 \mathrm{H}), 6.68(\mathrm{~s}, 2 \mathrm{H}), 6.56(\mathrm{~d}, J=8.8 \mathrm{~Hz}, 2 \mathrm{H}), 4.67(\mathrm{t}, J=7.6 \mathrm{~Hz}, 2 \mathrm{H})$, $3.63(\mathrm{t}, J=7.1 \mathrm{~Hz}, 2 \mathrm{H}), 2.12-2.05(\mathrm{~m}, 2 \mathrm{H}), 1.73-1.67(\mathrm{~m}, 2 \mathrm{H}), 1.54-1.45(\mathrm{~m}, 2 \mathrm{H}) .{ }^{13} \mathrm{C} \mathrm{NMR}$ (100 MHz, MeOD) $\delta(\mathrm{ppm}): 182.64,171.57,164.88,155.21,146.85,145.97,142.20,130.84$, $130.44,129.54,126.97,115.31,112.48,103.62,63.04,45.19,32.34,29.54,27.17,26.72$. MS: $\mathrm{m} / \mathrm{z}$ calcd for $[\mathrm{M}]^{+} \mathrm{C}_{32} \mathrm{H}_{30} \mathrm{~N}_{3} \mathrm{O}_{5} \mathrm{~S}, 568.1901$, found 568.1916, error $2.6 \mathrm{ppm}$. FT-IR $\left(\mathrm{cm}^{-1}\right)$ : 3053m, 2936s, 2675s, 2490m, 1752s, 1608s, 1541s, 1501s, 1487s, 1460s, 1329s, 1255s, 1207m, 1176s, 1108s, $849 \mathrm{~m}, 680 \mathrm{~m}$.

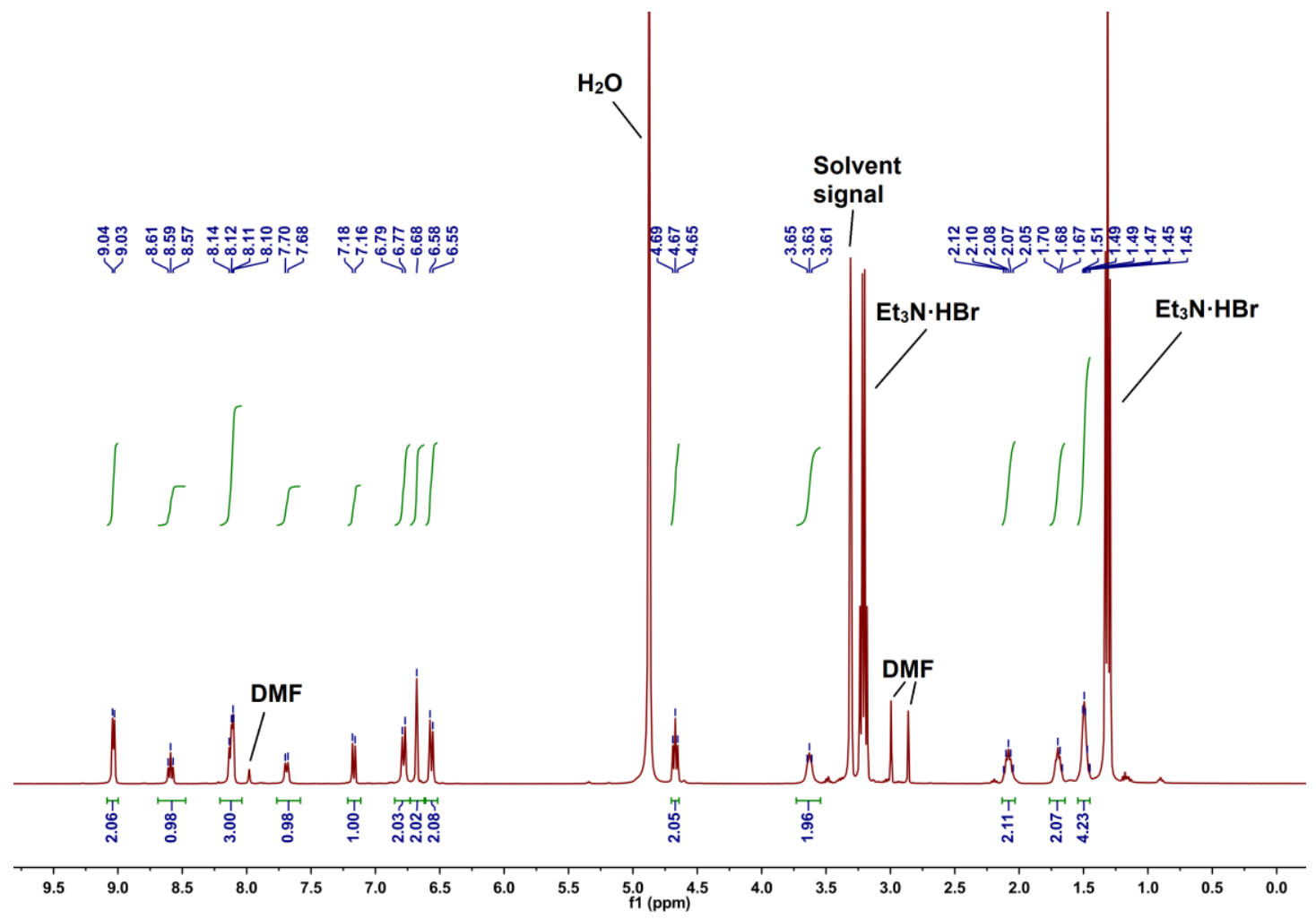

Figure S12. ${ }^{1} \mathrm{H}$ NMR spectrum (400 MHz, MeOD) recorded for FITC-Py. 


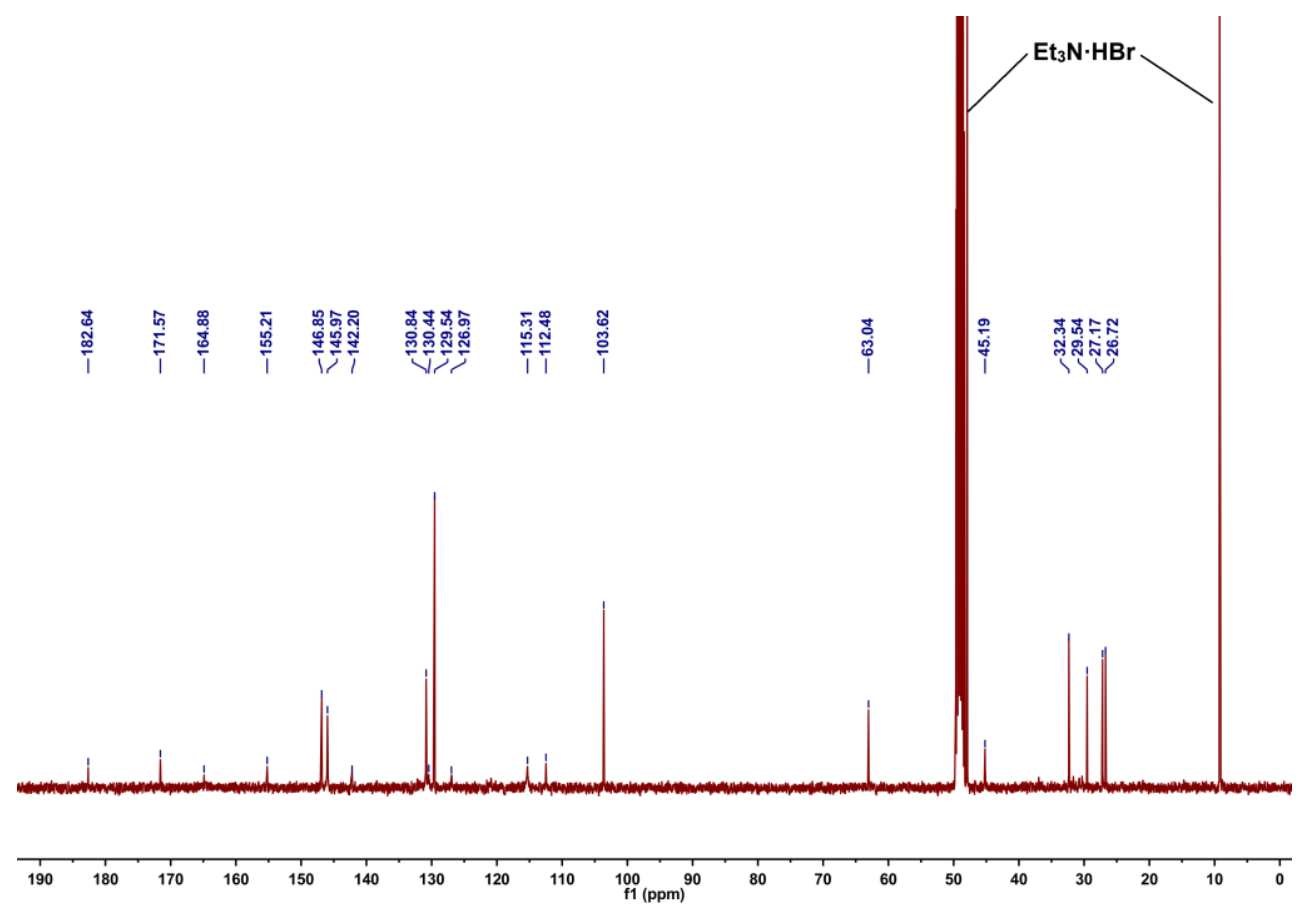

Figure S13. ${ }^{13} \mathrm{C}$ NMR spectrum (100 MHz, MeOD) of FITC-Py.

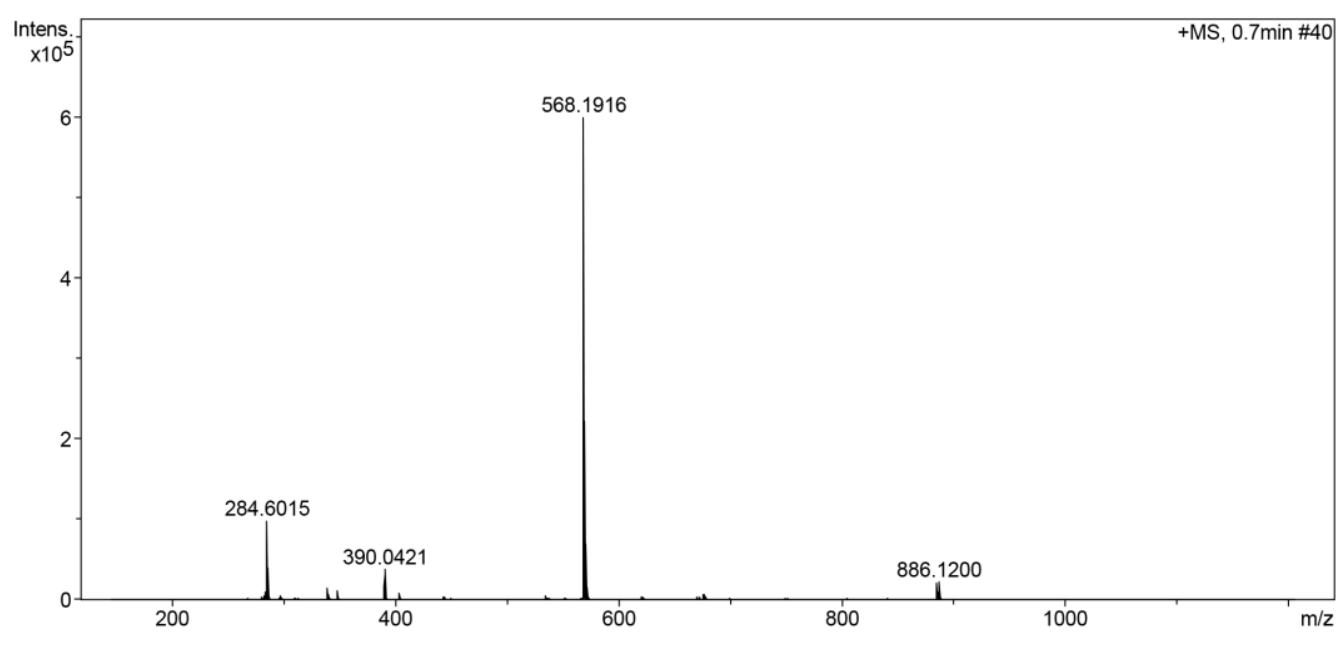

Figure S14. Electrospray ionization mass spectrum of FITC-Py. 
Synthesis of FA-Py ${ }^{5}$ : Folic acid (441 mg, $1 \mathrm{mmol}$ ) was activated by DCC (247 mg, $\left.1.2 \mathrm{mmol}\right)$ and NHS (230 mg, $2 \mathrm{mmol})$ in DMSO $(20 \mathrm{~mL})$ at $50{ }^{\circ} \mathrm{C}$ for $6 \mathrm{~h}$. Compound $5(340 \mathrm{mg}, 1 \mathrm{mmol})$ and $\mathrm{Et}_{3} \mathrm{~N}(200 \mu \mathrm{L})$ was added and the mixture was stirred for another $6 \mathrm{~h}$ at room temperature. The precipitate was removed by filtration and the filtrate was poured into acetone $(30 \mathrm{~mL})$. The product was collected by centrifugation and washed with acetone $(3 \times 30 \mathrm{~mL})$ to give a pale yellow solid (566 mg, 83 \%). $\quad{ }^{1} \mathrm{H}$ NMR (400 MHz, DMSO) $\delta$ (ppm): 9.10 (d, $\left.J=5.6 \mathrm{~Hz}, 2 \mathrm{H}\right), 8.64(\mathrm{~s}, 1 \mathrm{H})$, $8.60(\mathrm{t}, J=8.0 \mathrm{~Hz}, 1 \mathrm{H}), 8.15(\mathrm{t}, J=6.9 \mathrm{~Hz}, 2 \mathrm{H}), 8.10-7.95(\mathrm{~m}, 1 \mathrm{H}), 7.82(\mathrm{t}, J=5.8 \mathrm{~Hz}, 1 \mathrm{H}), 7.62$ $(\mathrm{d}, J=8.3 \mathrm{~Hz}, 2 \mathrm{H}), 7.17(\mathrm{~s}, 2 \mathrm{H}), 6.95(\mathrm{t}, J=6.2 \mathrm{~Hz}, 1 \mathrm{H}), 6.63(\mathrm{~d}, J=9.0 \mathrm{~Hz}, 2 \mathrm{H}), 4.63-4.53(\mathrm{~m}$, 2H), 4.53 - $4.40(\mathrm{~m}, 2 \mathrm{H}), 4.34-4.20(\mathrm{~m}, 1 \mathrm{H}), 3.04-2.97(\mathrm{~m}, 2 \mathrm{H}), 2.34-2.21(\mathrm{~m}, 1 \mathrm{H}), 2.18-2.14$ (m, 1H), $2.06-1.75(\mathrm{~m}, 4 \mathrm{H}), 1.39-1.18(\mathrm{~m}, 6 \mathrm{H}) \cdot{ }^{13} \mathrm{C}$ NMR (100 MHz, DMSO) $\delta(\mathrm{ppm}): 174.34$, $171.59,166.12,161.24,156.28,154.13,150.71,148.55,145.46,144.72,128.84,128.09,127.95$, 121.52, 111.21, 60.70, 52.60, 45.93, 38.19, 32.10, 30.61, 28.76, 27.06, 25.65, 25.05. MS: $\mathrm{m} / z$ calcd for $[\mathrm{M}]^{+} \mathrm{C}_{30} \mathrm{H}_{36} \mathrm{~N}_{9} \mathrm{O}_{5}, 602.2834$, found 602.2814 , error $3.3 \mathrm{ppm}$. FT-IR $\left(\mathrm{cm}^{-1}\right): 3257 \mathrm{~m}, 2933 \mathrm{~m}$, $2858 \mathrm{~m}, 1697 \mathrm{~s}, 1636 \mathrm{~s}, 1604 \mathrm{~s}, 1502 \mathrm{~s}, 1374 \mathrm{~m}, 1295 \mathrm{~m}, 1174 \mathrm{~s}, 1125 \mathrm{~m}, 768 \mathrm{~m}, 682 \mathrm{~m}$.

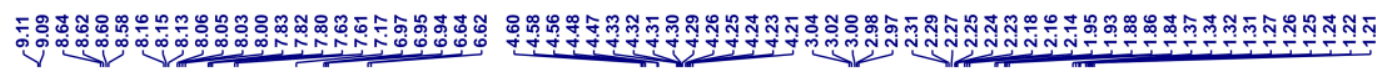

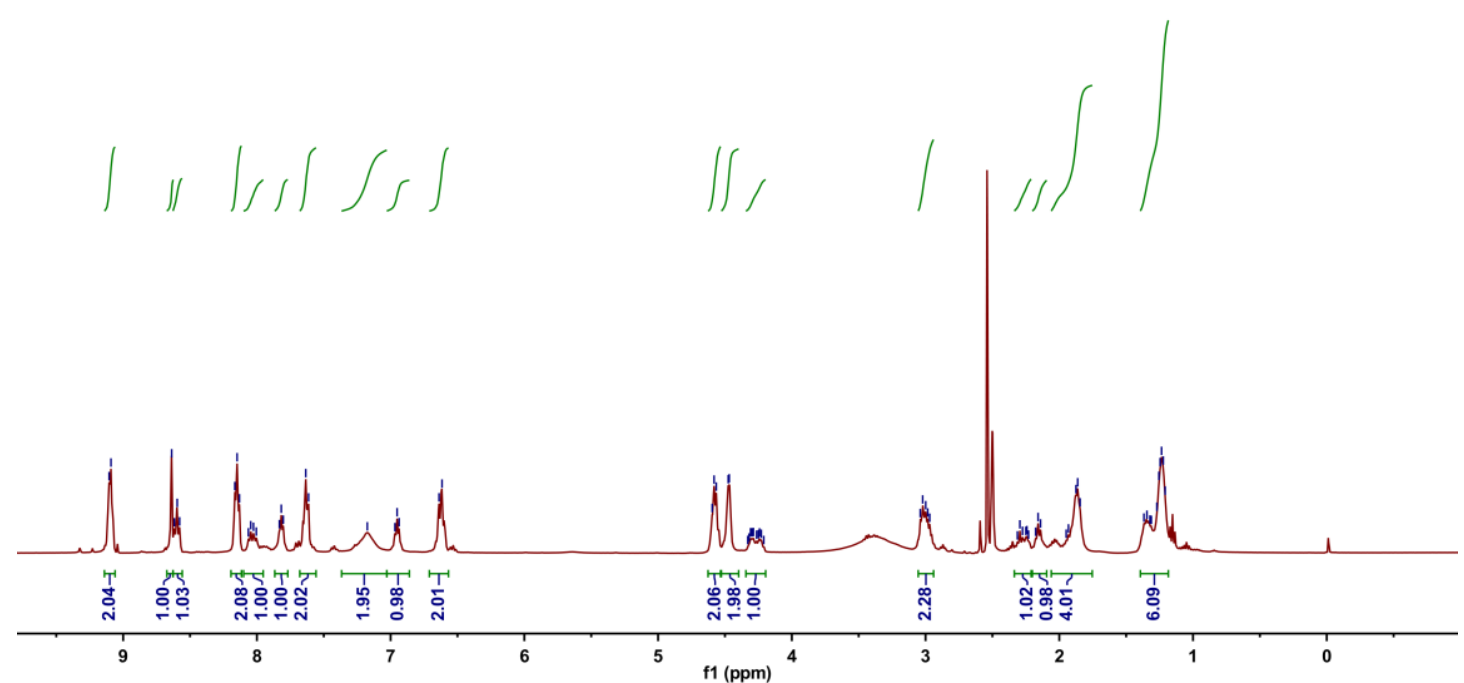

Figure S15. ${ }^{1} \mathrm{H}$ NMR spectrum (400 MHz, DMSO) recorded for FA-Py. 

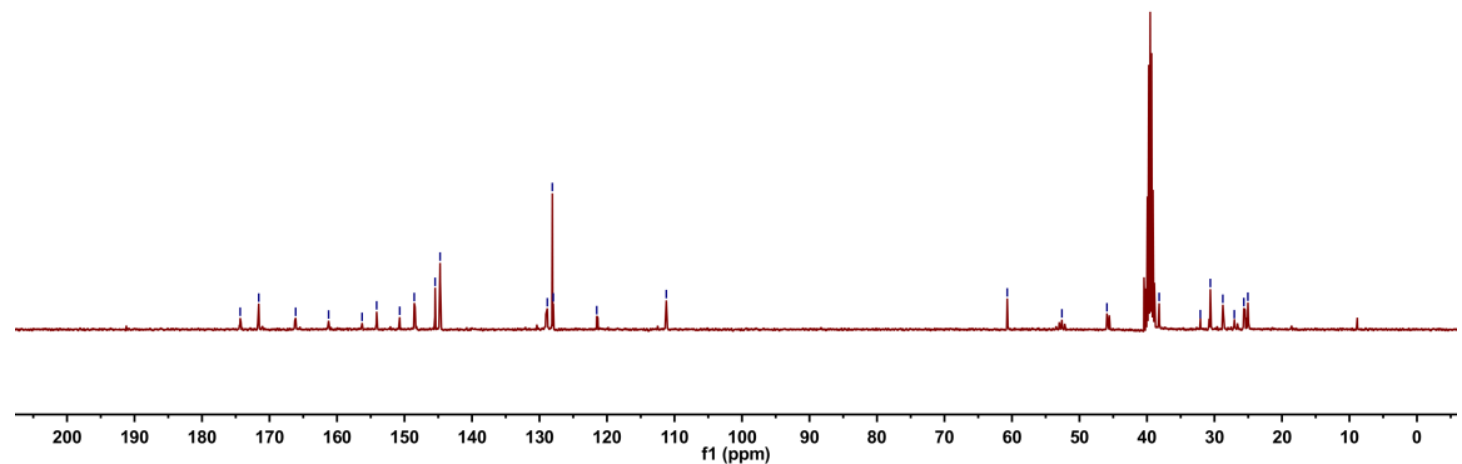

Figure S16. ${ }^{13} \mathrm{C}$ NMR spectrum (100 MHz, DMSO) recorded for FA-Py.

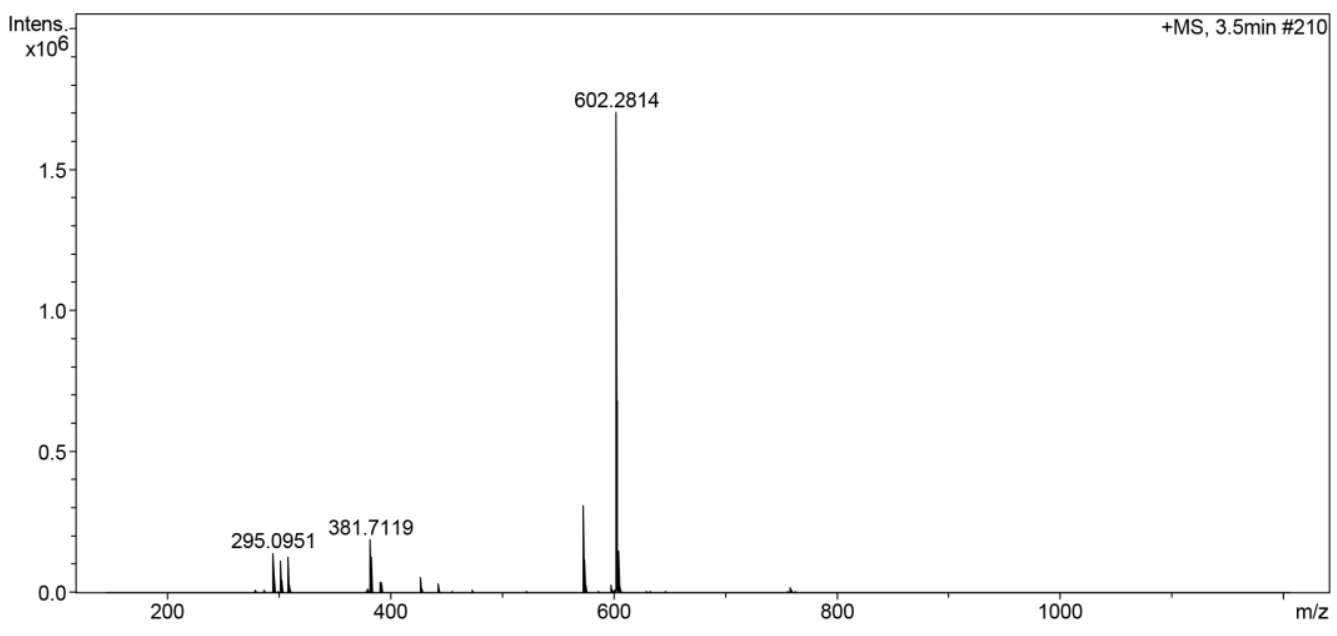

Figure S17. Electrospray ionization mass spectrum of FA-Py. 


\section{Host-Guest interaction}
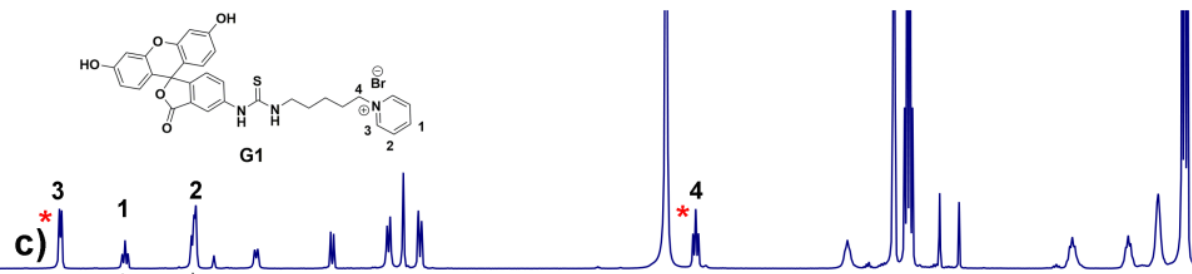

b)
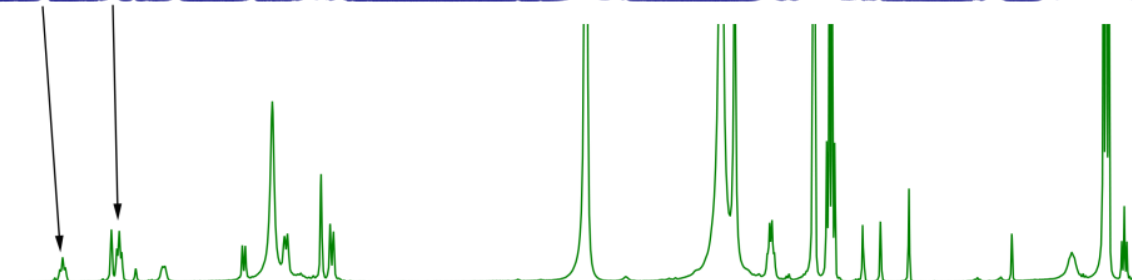

a)

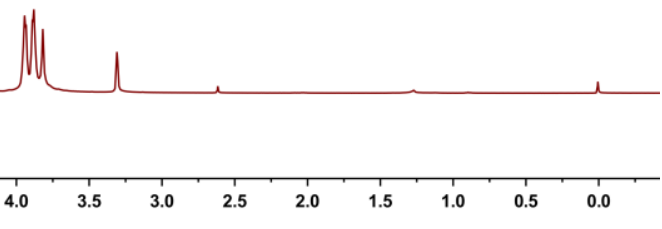

Figure S18. ${ }^{1} \mathrm{H}$ NMR spectra (400 MHz, MeOD) recorded for a) $\mathbf{1}$, b) 1 and FITC-Py (1:1) and c) FITC-Py.

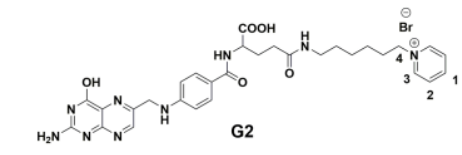

c) $d^{*} \int^{1} h a h a$

b)

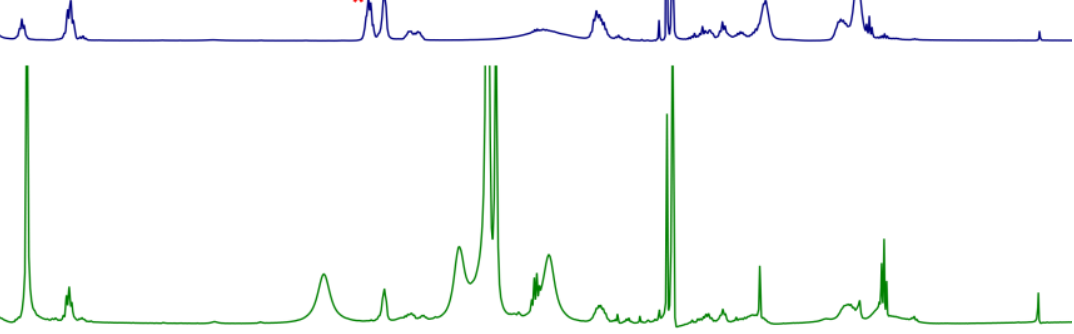

a)
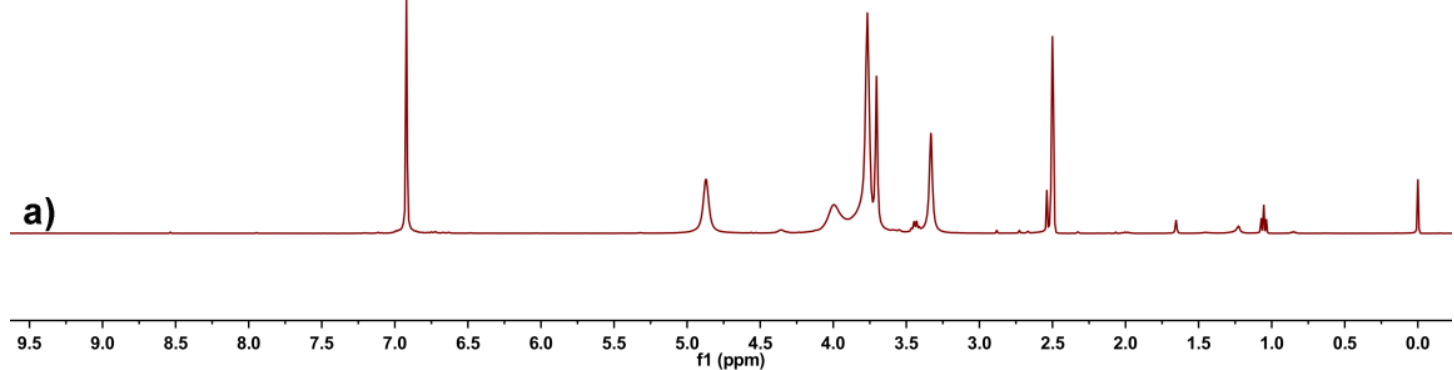

Figure S19. ${ }^{1} \mathrm{H}$ NMR spectra (400 MHz, DMSO) recorded for a) 1, b) 1 and FA-Py (1:1) and c) FA-Py. 


\section{FT-IR spectra}

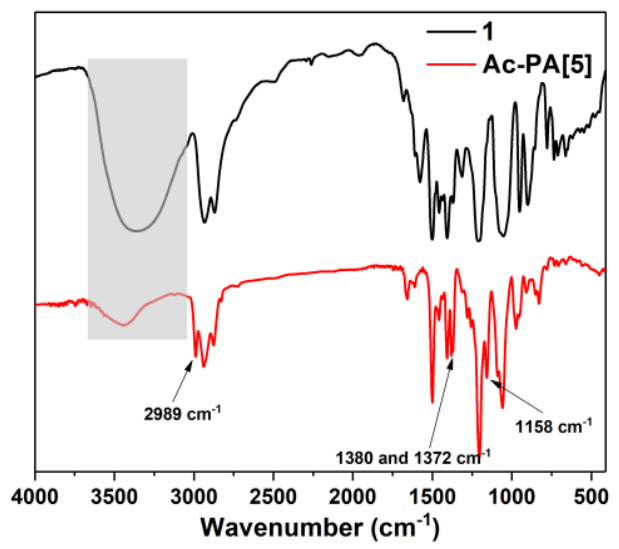

Figure S20. FT-IR spectra of 1 and Ac-PA[5] ${ }^{6}$

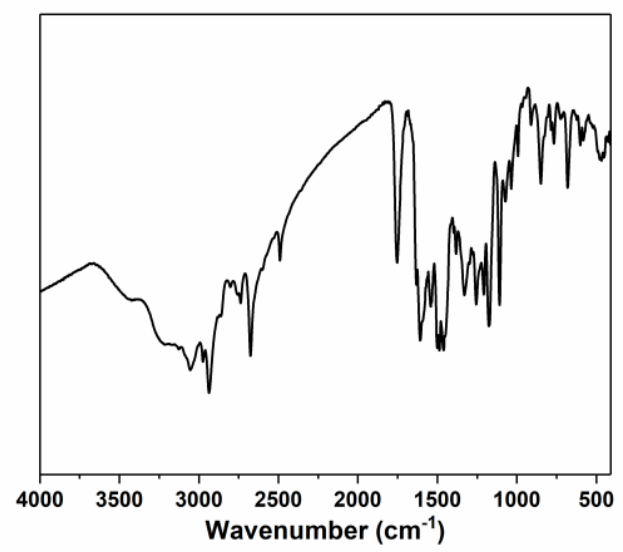

Figure S21. FT-IR spectrum of FITC-Py.

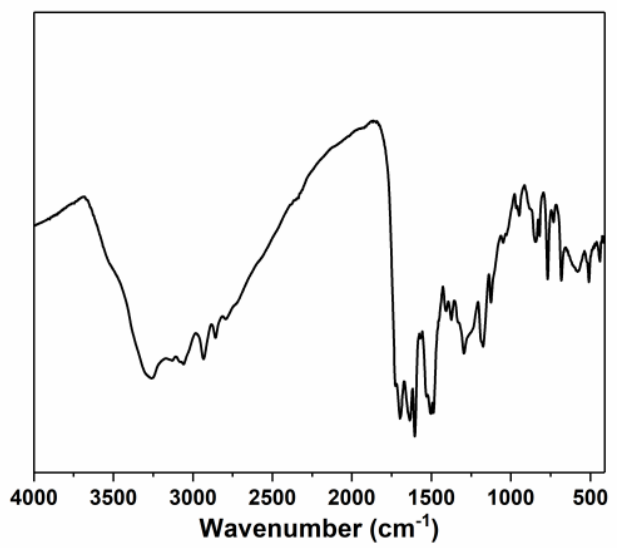

Figure S22. FT-IR spectrum of FA-Py. 
4. Morphology and size distributions of nanoparticles

a)

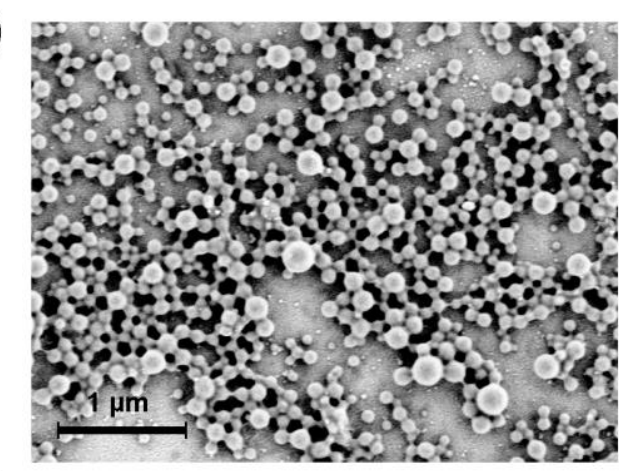

c)

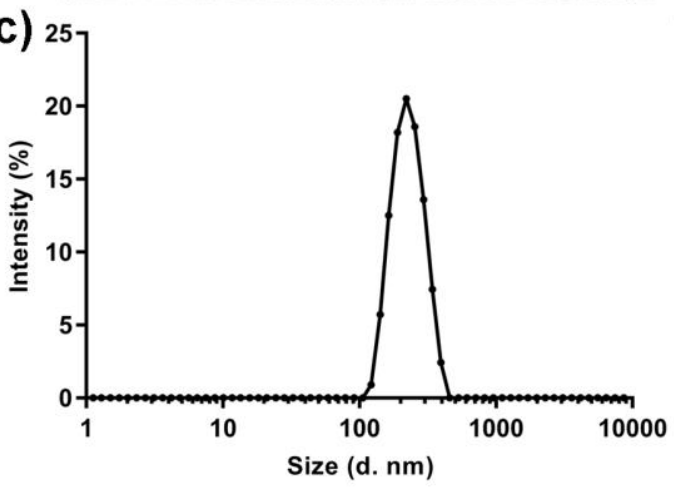

b)

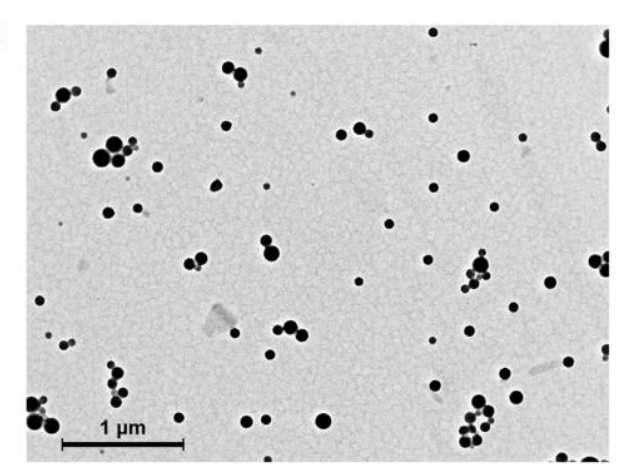

d)

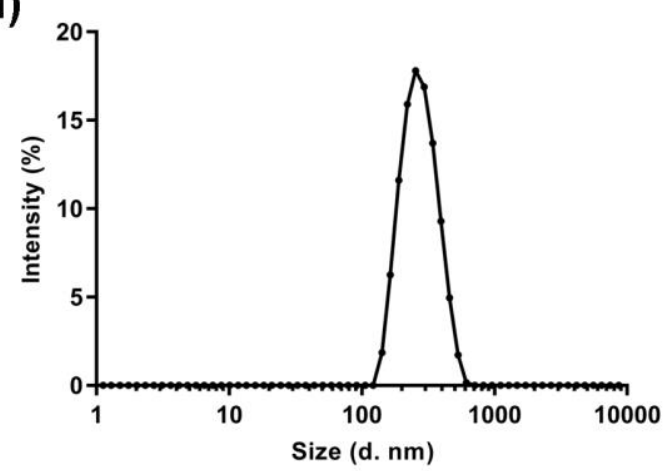

Figure S23. a) SEM, b) TEM images and c) size distribution curve of PTX-NPs (PDI $=0.222)$. d)

Size distribution curve of DOX-NPs (PDI $=0.120)$. 


\section{Time-dependent size change of nanoparticles}

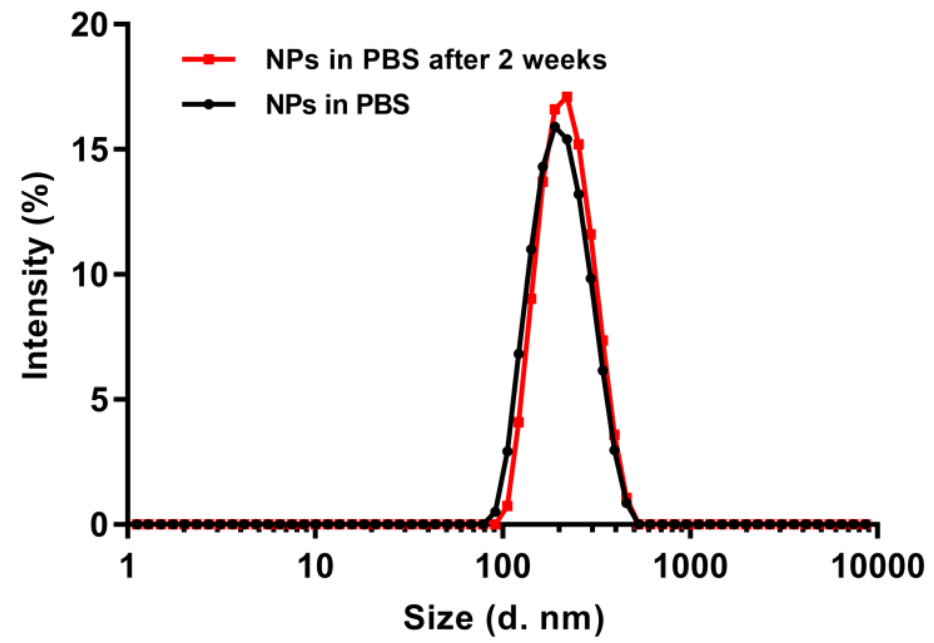

Figure S24. Time-dependent size distribution of blank nanoparticles in phosphate buffered saline (PBS). PDI (red line): 0.093.

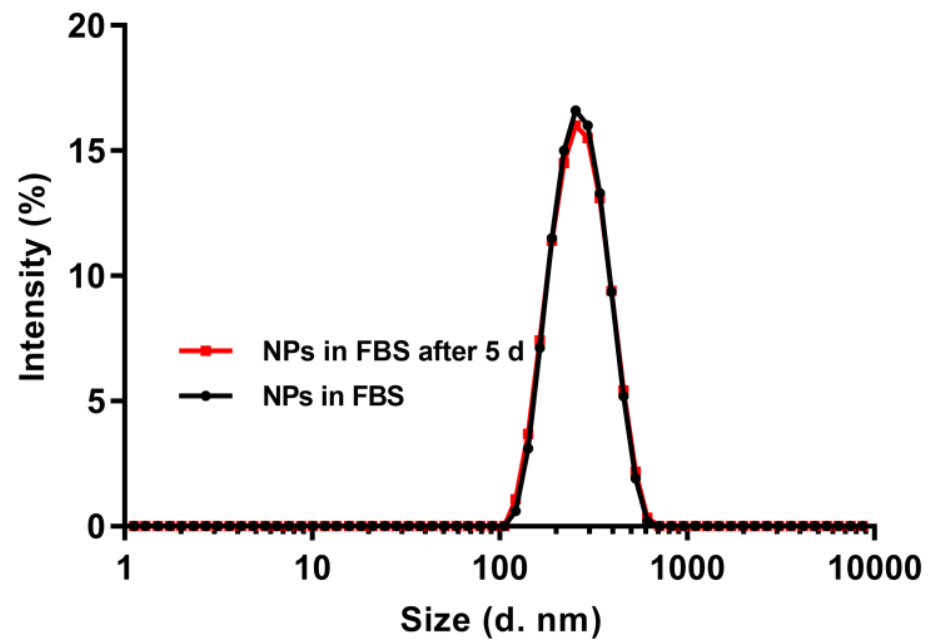

Figure S25. Time-dependent size distribution of blank nanoparticles in fetal bovine serum (FBS). PDI (black line): 0.180. PDI (red line): 0.248 . 


\section{References}

(1) Hu, X. B.; Chen, L.; Si, W.; Yu, Y.; Hou, J. L. Pillar[5]arene decaamine: Synthesis, encapsulation of very long linear diacids and formation of ion pair-stopped [2]rotaxanes. Chem. Commun. 2011, 47 (16), 4694.

(2) Bachelder, E. M.; Beaudette, T. T.; Broaders, K. E.; Dashe, J.; Fréchet, J. M. J. Acetalderivatized dextran: an acid-responsive biodegradable material for therapeutic applications. J. Am. Chem. Soc. 2008, 130 (32), 10494.

(3) Ding, C. Di; Liu, Y.; Wang, T.; Fu, J. J. Triple-stimuli-responsive nanocontainers assembled by water-soluble pillar[5]arene-based pseudorotaxanes for controlled release. J. Mater. Chem. B 2016, 4 (16), 2819.

(4) Hennig, A.; Borcherding, H.; Jaeger, C.; Hatami, S.; Würth, C.; Hoffmann, A.; Hoffmann, K.; Thiele, T.; Schedler, U.; Resch-Genger, U. Scope and limitations of surface functional group quantification methods: exploratory study with poly(acrylic acid)-grafted micro- and nanoparticles. J. Am. Chem. Soc. 2012, 134 (19), 8268.

(5) Liu, Y.; Dai, Z.; Wang, J.; Tu, Y.; Zhu, L. Folate-targeted pH-sensitive bortezomib conjugates for cancer treatment. Chem. Commun. 2019, 55 (29), 4254.

(6) Zhang, J.; Jia, Y.; Li, X.; Hu, Y.; Li, X. Facile engineering of biocompatible materials with pH-modulated degradability. Adv. Mater. 2011, 23 (27), 3035. 